\title{
Two Identification Methods for Dual-Rate Sampled-Data Nonlinear Output-Error Systems
}

\author{
Jing Chen ${ }^{1}$ and Ruifeng Ding ${ }^{2}$ \\ ${ }^{1}$ Wuxi Professional College of Science and Technology, Wuxi 214028, China \\ ${ }^{2}$ School of Electrical and Electronic Engineering, Hubei University of Technology, Wuhan 430068, China \\ Correspondence should be addressed to Jing Chen; chenjing1981929@126.com
}

Received 4 February 2014; Accepted 20 March 2014; Published 10 April 2014

Academic Editor: Ming Gao

Copyright (c) 2014 J. Chen and R. Ding. This is an open access article distributed under the Creative Commons Attribution License, which permits unrestricted use, distribution, and reproduction in any medium, provided the original work is properly cited.

\begin{abstract}
This paper presents two methods for dual-rate sampled-data nonlinear output-error systems. One method is the missing output estimation based stochastic gradient identification algorithm and the other method is the auxiliary model based stochastic gradient identification algorithm. Different from the polynomial transformation based identification methods, the two methods in this paper can estimate the unknown parameters directly. A numerical example is provided to confirm the effectiveness of the proposed methods.
\end{abstract}

\section{Introduction}

System identification plays an important part in many engineering applications [1-6]. Many identification methods assume that the input-output data at every sampling instant are available for linear systems [7-11] and nonlinear systems [12-20], which is usually not the case in practice. When the input and output signals of the systems have different sampling rates, these systems are usually called irregularly sampled-data systems [21-27], for example, dual-rate or multirate systems [28-30]. Dual-rate/multirate systems in which the input and the output are sampled at different frequencies arise widely in robust filtering and control [3133], adaptive control [34-37], and system identification [3843]. In the literature of dual-rate system identification, the socalled polynomial transformation technique is often used to transform the dual-rate model $[44,45]$.

As far as we know, the identification methods based on the polynomial transformation technique cannot directly estimate the parameters of the dual-rate system and the number of the unknown parameters to be estimated is more than the number of the unknown parameters of the original dual-rate system.

The nonlinear system consisting of a static nonlinear block followed by a linear dynamic system is called a Hammerstein system [46-49]. The nonlinearity of the Hammerstein system is usually expressed by some known basis functions $[50,51]$ or by a piece-wise polynomial function $[52,53]$. When the Hammerstein system is a dual-rate system and has a preload nonlinearity, to the best of our knowledge, there is no work on identification of such systems. The main contributions of this paper are presenting the two methods directly for estimating the parameters of the dualrate system. The proposed methods of this paper can combine the auxiliary model identification methods [54-57], the iterative identification methods [58-62], the multi-innovation identification methods [63-70], the hierarchical identification methods [71-83], and the two-stage or multistage identification methods $[84,85]$ to study identification problems for other linear systems [86-90] or nonlinear systems [91-97].

The rest of this paper is organized as follows. Section 2 introduces the dual-rate nonlinear output-error systems. Section 3 gives a missing output identification model based stochastic gradient algorithm. Section 4 provides an auxiliary model based stochastic gradient algorithm. Section 5 introduces an illustrative example. Finally, concluding remarks are given in Section 6. 


\section{Problem Formulation}

Let " $A=: X$ " or " $X:=A$ " stand for " $A$ is defined as $X$," let the norm of a column vector $X$ be $\|\mathbf{X}\|^{2}:=\operatorname{tr}\left[\mathbf{X}^{\mathrm{T}} \mathbf{X}\right]$, and let the superscript $\mathrm{T}$ denote the matrix transpose.

Consider the following dual-rate nonlinear output-error system with colored noise:

$$
y(t)=\frac{B(z)}{A(z)} f(u(t))+v(t),
$$

where $y(t)$ is the system output, $u(t)$ is the system input, $v(t)$ is a stochastic white noise with zero mean, $A(z)$ and $B(z)$ are the polynomials in the unit backward shift operator $\left[z^{-1} y(t)=\right.$ $y(t-1)]$,

$$
\begin{gathered}
A(z)=1+a_{1} z^{-1}+a_{2} z^{-2}+\cdots+a_{n} z^{-n}, \\
B(z)=b_{1} z^{-1}+b_{2} z^{-2}+\cdots+b_{n} z^{-n},
\end{gathered}
$$

and $f(u(t))$ is a preload nonlinearity shown in Figure 1 and can be expressed as $[98,99]$

$$
f(u(t))= \begin{cases}u(t)+m_{1}, & u(t)>0, \\ 0, & u(t)=0, \\ u(t)-m_{2}, & u(t)<0,\end{cases}
$$

where $m_{1}$ and $-m_{2}$ are two preload points.

For the dual-rate sampled-data system, all the input data $\{u(t), t=0,1,2, \ldots\}$ and only the scarce output data $\{y(t q)$, $t=0,1,2, \ldots,(q \geqslant 2)\}$ are known. The intersample outputs or missing outputs $y(t q+j), j=1,2, \ldots, q-1$ are unavailable.

Define a sign function

$$
\operatorname{sgn}(u(t)):= \begin{cases}1, & \text { if } u(t)>0, \\ 0, & \text { if } u(t)=0, \\ -1, & \text { if } u(t)<0 .\end{cases}
$$

Then the function $f(u(t))$ can be expressed as

$$
\begin{aligned}
f(u(t))= & u(t)+\frac{m_{1}+m_{2}}{2} \operatorname{sgn}(u(t)) \\
& +\frac{m_{1}-m_{2}}{2} \operatorname{sgn}\left(u^{2}(t)\right) .
\end{aligned}
$$

Let

$$
g_{1}=\frac{m_{1}+m_{2}}{2}, \quad g_{2}=\frac{m_{1}-m_{2}}{2} .
$$

Hence, we have

$$
f(u(t))=u(t)+g_{1} \operatorname{sgn}(u(t))+g_{2} \operatorname{sgn}\left(u^{2}(t)\right) .
$$

Once $g_{1}$ and $g_{2}$ are estimated, the parameters $m_{1}$ and $m_{2}$ can be computed by $m_{1}=g_{1}+g_{2}, m_{2}=g_{1}-g_{2}$.

\section{The Missing Outputs Identification Model Based Stochastic Gradient Algorithm}

Substituting (7) into (1) gets

$$
\begin{aligned}
A(z) y(t)= & B(z)\left(u(t)+g_{1} \operatorname{sgn}(u(t))+g_{2} \operatorname{sgn}\left(u^{2}(t)\right)\right) \\
& +A(z) v(t) .
\end{aligned}
$$

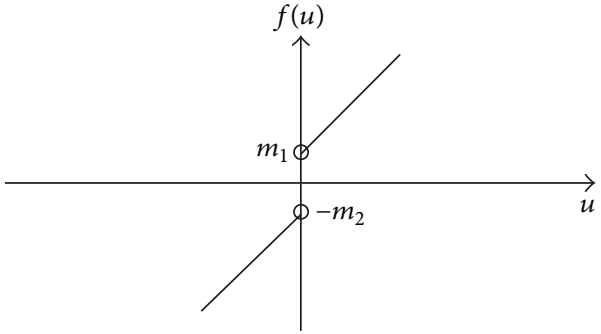

FIGURE 1: The preload characteristics.

Define the parameter vector $\boldsymbol{\theta}$ and information vector $\boldsymbol{\varphi}_{1}(t)$ as

$$
\begin{gathered}
\boldsymbol{\theta}:=\left[a_{1}, a_{2}, \ldots, a_{n}, b_{1}, b_{2}, \ldots, b_{n}, b_{1} g_{1}, b_{2} g_{1}, \ldots,\right. \\
\left.b_{n} g_{1}, b_{1} g_{2}, b_{2} g_{2}, \ldots, b_{n} g_{2}\right]^{\mathrm{T}} \in \mathbb{R}^{4 n},
\end{gathered}
$$

$$
\begin{aligned}
\varphi_{1}(t):=[ & -y(t-1)+v(t-1), \\
& -y(t-2)+v(t-2), \ldots,-y(t-n)+v(t-n), \\
& u(t-1), u(t-2), \ldots, u(t-n), \\
& \operatorname{sgn}(u(t-1)), \operatorname{sgn}(u(t-2)), \ldots, \\
& \operatorname{sgn}(u(t-n)), \operatorname{sgn}\left(u^{2}(t-1)\right), \\
& \left.\operatorname{sgn}\left(u^{2}(t-2)\right), \ldots, \operatorname{sgn}\left(u^{2}(t-n)\right)\right]^{\mathrm{T}} \in \mathbb{R}^{4 n} .
\end{aligned}
$$

From (9) and (10), we get

$$
y(t)=\boldsymbol{\varphi}_{1}^{\mathrm{T}}(t) \boldsymbol{\theta}+v(t)
$$

or

$$
y(t q)=\boldsymbol{\varphi}_{1}^{\mathrm{T}}(t q) \boldsymbol{\theta}+v(t q) .
$$

Let $\widehat{\boldsymbol{\theta}}(t)$ be the estimate of $\boldsymbol{\theta}$. Defining and minimizing the cost function

$$
J(\boldsymbol{\theta}):=\left[y(t q)-\boldsymbol{\varphi}_{1}^{\mathrm{T}}(t q) \boldsymbol{\theta}\right]^{2}
$$

give the following stochastic gradient (SG) algorithm for estimating $\boldsymbol{\theta}$ :

$$
\begin{gathered}
\hat{\boldsymbol{\theta}}(t q)=\hat{\boldsymbol{\theta}}(t q-q)+\frac{\widehat{\boldsymbol{\varphi}}_{1}(t q)}{r_{1}(t q)} e_{1}(t q), \\
\widehat{\boldsymbol{\theta}}(t q-i)=\widehat{\boldsymbol{\theta}}(t q-q), \quad i=q-1, q-2, \ldots, 1, \\
e_{1}(t q)=y(t q)-\widehat{\boldsymbol{\varphi}}_{1}^{\mathrm{T}}(t q) \hat{\boldsymbol{\theta}}(t q-q),
\end{gathered}
$$




$$
\begin{aligned}
& \widehat{\boldsymbol{\varphi}}_{1}(t q)=[-y(t q-1)+\widehat{v}(t q-1), \\
&-y(t q-2)+\widehat{v}(t q-2), \ldots, \\
&-y(t q-n)+\widehat{v}(t q-n), \\
& u(t-1), u(t-2), \ldots, u(t-n), \\
& \operatorname{sgn}(u(t-1)), \operatorname{sgn}(u(t-2)), \ldots, \\
& \operatorname{sgn}(u(t-n)), \operatorname{sgn}\left(u^{2}(t-1)\right), \\
&\left.\operatorname{sgn}\left(u^{2}(t-2)\right), \ldots, \operatorname{sgn}\left(u^{2}(t-n)\right)\right]^{\mathrm{T}}, \\
& \widehat{v}(t q-i)=y(t q-i)-\widehat{\boldsymbol{\varphi}}_{1}^{\mathrm{T}}(t q-i) \hat{\boldsymbol{\theta}}(t q-i), \\
& r_{1}(t q)=r_{1}(t q-q)+\left\|\widehat{\boldsymbol{\varphi}}_{1}(t q)\right\|^{2}, \quad r(0)=1 .
\end{aligned}
$$

Since the information $\widehat{\varphi}_{1}(t q)$ on the right-hand sides of (16) contains the unknown variables $-y(t q-i)+\widehat{v}(t q-i), i=$ $q-1, q-2, \ldots, 1$, the SG algorithm in (14)-(18) is impossible to implement. In this section, we use the missing outputs identification model (MOI) to overcome this difficulty; these unknown $-y(t q-i)+\widehat{v}(t q-i)$ are replaced with the output estimates $-\widehat{y}(t q-i)+\widehat{v}(t q-i)$ of an MOI model,

$$
\begin{aligned}
& -\widehat{y}(t q-i)+\widehat{v}(t q-i)=-\widehat{\boldsymbol{\varphi}}_{1}^{\mathrm{T}}(t q-i) \hat{\boldsymbol{\theta}}(t q-i), \\
& \quad i=q-1, q-2, \ldots, 1, \\
& \widehat{\boldsymbol{\varphi}}_{1}(t q-i+1) \\
& =[-\widehat{y}(t q-i)+\widehat{v}(t q-i), \\
& \quad-\hat{y}(t q-i-1)+\widehat{v}(t q-i-1), \ldots, \\
& \quad-\hat{y}(t q-q+1)+\widehat{v}(t q-q+1), \\
& \quad-y(t q-q)+\widehat{v}(t q-q), \ldots, \\
& \quad-\hat{y}(t q-i+1-n)+\widehat{v}(t q-i+1-n), \\
& u(t q-i), u(t q-i-1), \ldots, \\
& u(t q-i+1-n), \operatorname{sgn}(u(t q-i)), \\
& \operatorname{sgn}(u(t q-i-1)), \ldots, \\
& \operatorname{sgn}(u(t q-i+1-n)), \operatorname{sgn}\left(u^{2}(t q-i)\right), \\
& \operatorname{sgn}\left(u^{2}(t q-i-1)\right), \ldots, \\
& \left.\operatorname{sgn}\left(u^{2}(t q-i+1-n)\right)\right]^{\mathrm{T}},
\end{aligned}
$$

where $-\widehat{y}(t q-i)+\widehat{v}(t q-i)$ represents the estimate of $-y(t q-$ $i)+v(t q-i)$ at time $t q-i, \widehat{\boldsymbol{\theta}}(t q-i)$ represents the estimate of $\boldsymbol{\theta}$ at time $t q-i$, and $\widehat{\boldsymbol{\varphi}}_{1}(t q-i)$ represents the estimate of $\varphi_{1}(q-i)$.
Thus, we have the following missing output estimates based SG (MOE-SG) algorithm for estimating the parameter vector $\boldsymbol{\theta}$ in (9):

$$
\begin{aligned}
& \widehat{\boldsymbol{\theta}}(t q)=\widehat{\boldsymbol{\theta}}(t q-q)+\frac{\widehat{\boldsymbol{\varphi}}_{1}(t q)}{r_{1}(t q)} e_{2}(t q), \\
& \widehat{\boldsymbol{\theta}}(t q-i)=\widehat{\boldsymbol{\theta}}(t q-q), \quad i=q-1, q-2, \ldots, 1, \\
& -\widehat{y}(t q-i)+\widehat{v}(t q-i)=-\widehat{\boldsymbol{\varphi}}_{1}^{\mathrm{T}}(t q-i) \hat{\boldsymbol{\theta}}(t q-i), \\
& \widehat{\boldsymbol{\varphi}}_{1}(t q-i+1) \\
& =[-\widehat{y}(t q-i)+\widehat{v}(t q-i), \\
& -\widehat{y}(t q-i-1)+\widehat{v}(t q-i-1), \ldots, \\
& -\widehat{y}(t q-q+1)+\widehat{v}(t q-q+1), \\
& -y(t q-q)+\hat{v}(t q-q), \ldots, \\
& -\hat{y}(t q-i+1-n)+\hat{v}(t q-i+1-n), \\
& u(t q-i), u(t q-i-1), \ldots, \\
& u(t q-i+1-n), \operatorname{sgn}(u(t q-i)), \\
& \operatorname{sgn}(u(t q-i-1)), \ldots, \operatorname{sgn}(u(t q-i+1-n)), \\
& \operatorname{sgn}\left(u^{2}(t q-i)\right), \operatorname{sgn}\left(u^{2}(t q-i-1)\right), \ldots, \\
& \left.\operatorname{sgn}\left(u^{2}(t q-i+1-n)\right)\right]^{\mathrm{T}} \\
& e_{1}(t q)=y(t q)-\widehat{\boldsymbol{\varphi}}_{1}^{\mathrm{T}}(t q) \widehat{\boldsymbol{\theta}}(t q-q), \\
& r_{1}(t q)=r_{1}(t q-q)+\left\|\widehat{\boldsymbol{\varphi}}_{1}(t q)\right\|^{2}, \quad r(0)=1 .
\end{aligned}
$$

The steps of computing the parameter estimate $\widehat{\boldsymbol{\theta}}(t q)$ by the MOE-SG algorithm are listed as follows.

(1) Let $u(-j)=0, y(-j)=0, j=0,1,2, \ldots, n-1$, and give a small positive number $\varepsilon$.

(2) Let $t=1, r(0)=1$, and $\widehat{\boldsymbol{\theta}}(0)=\mathbf{1} / p_{0}$ with $\mathbf{1}$ being a column vector whose entries are all unity and $p_{0}=$ $10^{6}$.

(3) Collect the input data $u(t q), u(t q-1), \ldots, u(t q-n)$, and collect the output data $y(t q)$.

(4) Let $i=q-1$ and compute $-\widehat{y}(t q-i)+\widehat{v}(t q-i)$ by (22).

(5) Form $\widehat{\varphi}_{1}(t q-i+1)$ by (23).

(6) Decrease $i$ by 1 ; if $i \geqslant 1$, go to step (4); otherwise, go to the next step.

(7) Compute $e_{1}(t q)$ and $r_{1}(t q)$ by (24) and (25), respectively.

(8) Update the parameter estimation vector $\widehat{\boldsymbol{\theta}}(t q)$ by (20).

(9) Compare $\widehat{\boldsymbol{\theta}}(t q)$ and $\widehat{\boldsymbol{\theta}}(t q-q)$; if $\|\widehat{\boldsymbol{\theta}}(t q)-\widehat{\boldsymbol{\theta}}(t q-q)\| \leqslant$ $\varepsilon$, then terminate the procedure and obtain the $\widehat{\boldsymbol{\theta}}(t q)$; otherwise, increase $t$ by 1 and go to step (3). 


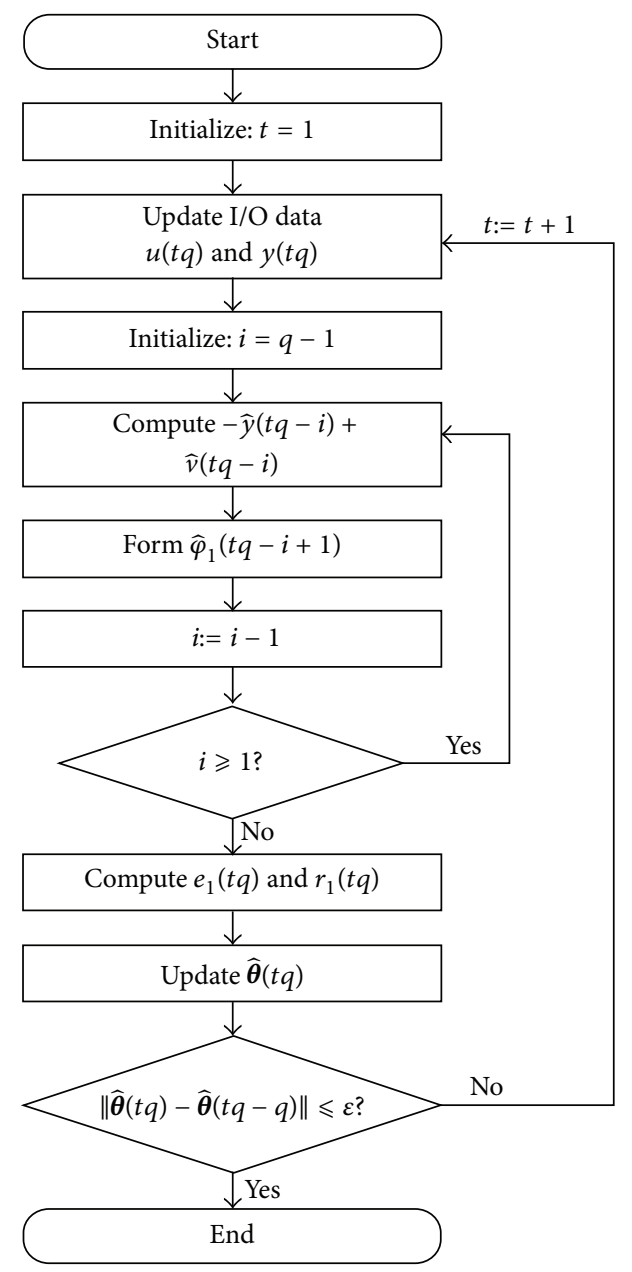

FIGURE 2: The flowchart of computing the estimate $\widehat{\boldsymbol{\theta}}(t q)$.

The flowchart of computing the MOE-SG parameter estimate $\widehat{\boldsymbol{\theta}}(t q)$ is shown in Figure 2.

\section{The Auxiliary Model Based Stochastic Gradient Algorithm}

Define

$$
x(t)=\frac{B(z)}{A(z)}\left(u(t)+g_{1} \operatorname{sgn}(u(t))+g_{2} \operatorname{sgn}\left(u^{2}(t)\right)\right) .
$$

From (8) and (26), we have

$$
y(t)=x(t)+v(t) .
$$

Define the information vector $\varphi_{2}(t)$ as

$$
\begin{aligned}
\varphi_{2}(t):=[- & x(t-1),-x(t-2), \ldots,-x(t-n), \\
& u(t-1), u(t-2), \ldots, u(t-n), \\
& \operatorname{sgn}(u(t-1)), \operatorname{sgn}(u(t-2)), \ldots, \\
& \operatorname{sgn}(u(t-n)),
\end{aligned}
$$

$$
\begin{aligned}
& \operatorname{sgn}\left(u^{2}(t-1)\right), \operatorname{sgn}\left(u^{2}(t-2)\right), \ldots, \\
& \left.\operatorname{sgn}\left(u^{2}(t-n)\right)\right]^{\mathrm{T}} \in \mathbb{R}^{4 n} .
\end{aligned}
$$

Then we get

$$
\begin{gathered}
x(t)=\boldsymbol{\varphi}_{2}^{\mathrm{T}}(t) \boldsymbol{\theta}, \\
y(t)=\boldsymbol{\varphi}_{2}^{\mathrm{T}}(t) \boldsymbol{\theta}+v(t) .
\end{gathered}
$$

Assume $t$ is an integer multiple of $q$ and rewrite (30) as

$$
y(t q)=\varphi_{2}^{\mathrm{T}}(t q) \boldsymbol{\theta}(t q)+v(t q)
$$

Let $\widehat{\boldsymbol{\theta}}(t)$ be the estimate of $\boldsymbol{\theta}$. Defining and minimizing the cost function

$$
J(\boldsymbol{\theta}):=\left[y(t q)-\boldsymbol{\varphi}_{2}^{\mathrm{T}}(t q) \boldsymbol{\theta}\right]^{2}
$$

give the following SG algorithm of estimating $\boldsymbol{\theta}$ :

$$
\begin{gathered}
\hat{\boldsymbol{\theta}}(t q)=\hat{\boldsymbol{\theta}}(t q-q)+\frac{\boldsymbol{\varphi}_{2}(t q)}{r_{2}(t q)} e_{2}(t q), \\
e_{2}(t q)=y(t q)-\boldsymbol{\varphi}_{2}^{\mathrm{T}}(t q) \hat{\boldsymbol{\theta}}(t q-q), \\
\boldsymbol{\varphi}_{2}(t q)=[-x(t q-1),-x(t q-2), \ldots,-x(t q-n), \\
u(t-1), u(t-2), \ldots, u(t-n), \\
\operatorname{sgn}(u(t-1)), \operatorname{sgn}(u(t-2)), \ldots, \\
\operatorname{sgn}(u(t-n)), \\
\operatorname{sgn}\left(u^{2}(t-1)\right), \operatorname{sgn}\left(u^{2}(t-2)\right), \ldots, \\
\left.\operatorname{sgn}\left(u^{2}(t-n)\right)\right]^{\mathrm{T}}, \\
r_{2}(t q)= \\
r_{2}(t q-q)+\left\|\boldsymbol{\varphi}_{2}(t q)\right\|^{2}, \quad r(0)=1 .
\end{gathered}
$$

Because of the unknown variables $x(t q-i)$ in (33), the SG algorithm in (33)-(36) is impossible to implement. In this section, we use the auxiliary model; these unknown $x(t q-i)$ are replaced with the outputs $x_{a}(t q-i)$ of an auxiliary model,

$$
x_{a}(t q-i)=\boldsymbol{\theta}_{a}^{\mathrm{T}}(t q-i) \boldsymbol{\varphi}_{a}(t q-i),
$$

where $\boldsymbol{\theta}_{a}(t q-i)$ is the estimate $\widehat{\boldsymbol{\theta}}(t q-i)$ of $\boldsymbol{\theta}$ and $\boldsymbol{\varphi}_{a}(t q-i)$ is the estimate $\widehat{\boldsymbol{\varphi}}_{2}(t q-i)$ of $\boldsymbol{\varphi}_{2}(t q-i)$. We can obtain an auxiliary model based stochastic gradient (AM-SG) algorithm:

$$
\begin{gathered}
\widehat{\boldsymbol{\theta}}(t q)=\widehat{\boldsymbol{\theta}}(t q-q)+\frac{\widehat{\boldsymbol{\varphi}}_{2}(t q)}{r_{2}(t q)} e_{2}(t q), \\
\widehat{\boldsymbol{\theta}}(t q-i)=\widehat{\boldsymbol{\theta}}(t q-q), \quad i=q-1, q-2, \ldots, 1, \\
x_{a}(t q-i)=\widehat{\boldsymbol{\theta}}^{\mathrm{T}}(t q-i) \widehat{\boldsymbol{\varphi}}_{2}(t q-i),
\end{gathered}
$$




$$
\begin{aligned}
& \widehat{\boldsymbol{\varphi}}_{2}(t q-i+1)=[-x_{a}(t q-i),-x_{a}(t q-i-1), \ldots, \\
&-x_{a}(t q-i+1-n), \\
& u(t-i), u(t-i-1), \ldots, \\
& u(t-i+1-n), \\
& \operatorname{sgn}(u(t-i)), \operatorname{sgn}(u(t-i-1)), \ldots, \\
& \operatorname{sgn}(u(t-i+1-n)), \\
& \operatorname{sgn}\left(u^{2}(t-i)\right), \\
& \operatorname{sgn}\left(u^{2}(t-i-1)\right), \ldots, \\
&\left.\operatorname{sgn}\left(u^{2}(t-i+1-n)\right)\right]^{\mathrm{T}}, \\
& r_{2}(t q)=r_{2}(t q-q)+\left\|\widehat{\boldsymbol{\varphi}}_{2}(t q)\right\|^{2}, \quad r(0)=1 . \\
& e_{2}(t q)= y(t q)-\widehat{\boldsymbol{\varphi}}_{2}^{\mathrm{T}}(t q) \widehat{\boldsymbol{\theta}}(t q-q), \\
&
\end{aligned}
$$

The steps of computing the parameter estimate $\widehat{\boldsymbol{\theta}}(t q)$ by the AM-SG algorithm are listed as follows.

(1) Let $u(-j)=0, y(-j)=0, x(-j)=0, j=0,1,2, \ldots, n-$ 1 , and give a small positive number $\varepsilon$.

(2) Let $t=1, r(0)=1$, and $\widehat{\boldsymbol{\theta}}(0)=\mathbf{1} / p_{0}$ with $\mathbf{1}$ being a column vector whose entries are all unity and $p_{0}=$ $10^{6}$.

(3) Collect the input data $u(t q), u(t q-1), \ldots, u(t q-n)$, and collect the output data $y(t q)$.

(4) Let $i=q-1$ and compute $x_{a}(t q-i)$ by $(40)$.

(5) Form $\widehat{\varphi}_{2}(t q-i+1)$ by (41).

(6) Decrease $i$ by 1 ; if $i \geqslant 1$, go to step (4); otherwise, go to next step.

(7) Compute $e_{2}(t q)$ and $r_{2}(t q)$ by (42) and (43), respectively.

(8) Update the parameter estimation vector $\widehat{\boldsymbol{\theta}}(\mathrm{tq})$ by (38).

(9) Compare $\widehat{\boldsymbol{\theta}}(t q)$ and $\widehat{\boldsymbol{\theta}}(t q-q)$; if $\|\widehat{\boldsymbol{\theta}}(t q)-\widehat{\boldsymbol{\theta}}(t q-q)\| \leqslant$ $\varepsilon$, then terminate the procedure and obtain the $\widehat{\boldsymbol{\theta}}(\mathrm{tq})$; otherwise, increase $t$ by 1 and go to step (3).

The flowchart of computing the AM-SG parameter estimate $\widehat{\boldsymbol{\theta}}(t q)$ is shown in Figure 3 .

Remark 1. Compared with the polynomial transformation technique, the MOE-SG method and the AM-SG method can estimate the unknown parameters directly.

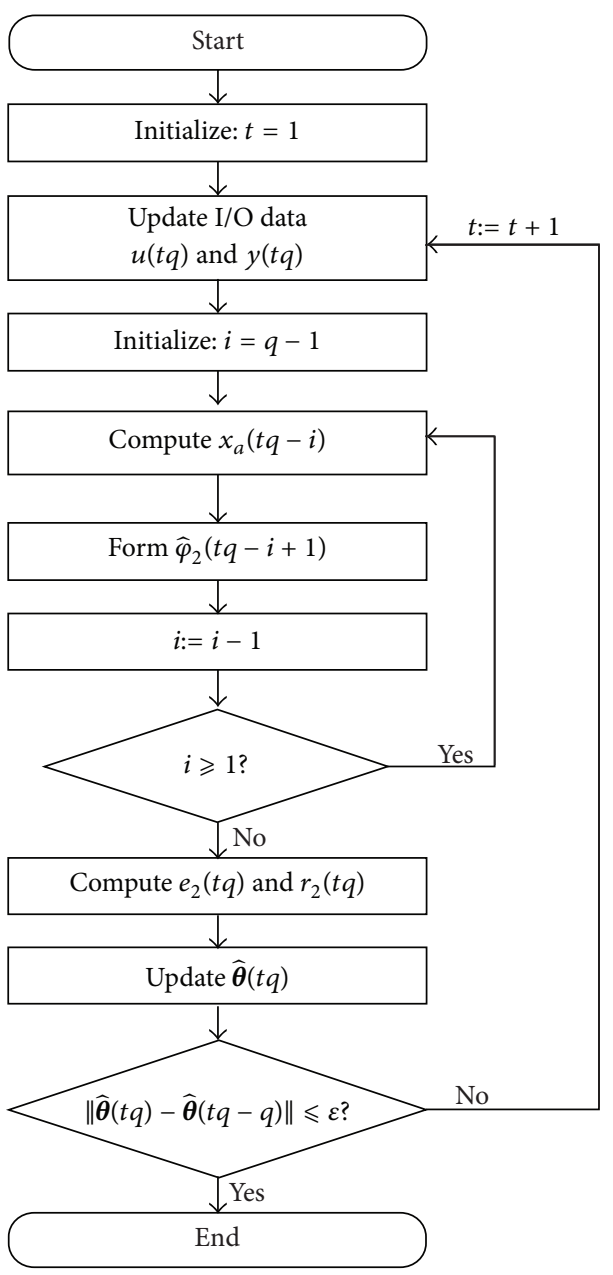

FIGURE 3: The flowchart of computing the estimate $\widehat{\boldsymbol{\theta}}_{2}(t q)$.

\section{Example}

Consider the following nonlinear output-error system with the updating period $q=2$ :

$$
\begin{gathered}
y(t)=\frac{B(z)}{A(z)} f(u(t))+v(t) \\
A(z)=1+a_{1} z^{-1}+a_{2} z^{-2}=1+0.49 z^{-1}-0.2 z^{-2}, \\
B(z)=b_{1} z^{-1}+b_{2} z^{-2}=0.2 z^{-1}+0.4 z^{-2}, \\
f(u(t))=u(t)+\frac{m_{1}+m_{2}}{2} \operatorname{sgn}(u(t)) \\
+\frac{m_{1}-m_{2}}{2} \operatorname{sgn}\left(u^{2}(t)\right) \\
=u(t)+\frac{0.5+0.3}{2} \operatorname{sgn}(u(t)) \\
+\frac{0.5-0.3}{2} \operatorname{sgn}\left(u^{2}(t)\right)
\end{gathered}
$$


TABLE 1: The MOE-SG algorithm estimates and errors.

\begin{tabular}{lcccccc}
\hline$t$ & 1000 & 2000 & 3000 & 4000 & 5000 & True values \\
\hline$a_{1}$ & 0.30790 & 0.43409 & 0.48162 & 0.49513 & 0.49505 & 0.49000 \\
$a_{2}$ & -0.16601 & -0.20319 & -0.20626 & -0.20656 & -0.20341 & 0.19816 \\
$b_{1}$ & 0.19508 & 0.19548 & 0.19462 & 0.19665 & 0.20000 \\
$b_{2}$ & 0.36487 & 0.39043 & 0.39879 & 0.40105 & 0.089705 & 0.40000 \\
$b_{1} g_{1}$ & 0.09729 & 0.09384 & 0.08995 & 0.08769 & 0.15867 & 0.08000 \\
$b_{2} g_{1}$ & 0.13565 & 0.14818 & 0.15401 & 0.027631 & 0.02770 & 0.02000 \\
$b_{1} g_{2}$ & 0.02161 & 0.02602 & 0.02558 & 0.03378 & 0.03385 \\
$b_{2} g_{2}$ & 0.02641 & 0.03181 & 0.03127 & 2.15284 & 1.91759 \\
\hline$\delta(\%)$ & 26.70140 & 8.46344 & 2.72656 & & 0.04000 \\
\hline
\end{tabular}

TABLE 2: The AM-SG algorithm estimates and errors.

\begin{tabular}{|c|c|c|c|c|c|c|}
\hline$t$ & 1000 & 2000 & 3000 & 4000 & 5000 & True values \\
\hline$a_{1}$ & 0.39201 & 0.46141 & 0.50310 & 0.49802 & 0.48917 & 0.49000 \\
\hline$a_{2}$ & -0.18980 & -0.19696 & -0.19784 & -0.20113 & -0.20307 & -0.20000 \\
\hline$b_{1}$ & 0.18974 & 0.19349 & 0.19872 & 0.20192 & 0.20281 & 0.20000 \\
\hline$b_{2}$ & 0.40122 & 0.41674 & 0.39648 & 0.40109 & 0.40350 & 0.40000 \\
\hline$b_{1} g_{1}$ & 0.09799 & 0.08924 & 0.08427 & 0.08475 & 0.08276 & 0.08000 \\
\hline$b_{2} g_{1}$ & 0.14716 & 0.15484 & 0.15489 & 0.16514 & 0.16040 & 0.16000 \\
\hline$b_{1} g_{2}$ & 0.02005 & 0.02781 & 0.02034 & 0.02761 & 0.02600 & 0.02000 \\
\hline$b_{2} g_{2}$ & 0.02674 & 0.03708 & 0.02712 & 0.03682 & 0.03467 & 0.04000 \\
\hline$\delta(\%)$ & 14.27547 & 5.08770 & 2.79209 & 1.91002 & 1.41209 & \\
\hline
\end{tabular}

$$
\begin{aligned}
& =u(t)+g_{1} \operatorname{sgn}(u(t))+g_{2} \operatorname{sgn}\left(u^{2}(t)\right) \\
& =u(t)+0.4 \operatorname{sgn}(u(t))+0.1 \operatorname{sgn}\left(u^{2}(t)\right) ;
\end{aligned}
$$

the input $\{u(t)\}$ is taken as a persistent excitation signal sequence with zero mean and unit variance and $\{v(t)\}$ is a white noise sequence with zero mean and variance $\sigma^{2}=$ $0.10^{2}$. The unknown parameters are as follows:

$$
\begin{aligned}
\boldsymbol{\theta} & =\left[a_{1}, a_{2}, b_{1}, b_{2}, b_{1} g_{1}, b_{2} g_{1}, b_{1} g_{2}, b_{2} g_{2}\right]^{\mathrm{T}} \\
& =[0.49,-0.2,0.2,0.4,0.08,0.16,0.02,0.04]^{\mathrm{T}} .
\end{aligned}
$$

Applying the MOE-SG algorithm and the AM-SG algorithm to estimate the parameters, the parameter estimates and their errors based on the MOE-SG algorithm and the AM-SG algorithm are shown in Tables 1 and 2 and the parameter estimation errors $\delta:=\|\widehat{\boldsymbol{\theta}}-\boldsymbol{\theta}\| /\|\boldsymbol{\theta}\|$ versus $t$ are shown in Figures 4 and 5 .

From Tables 1 and 2 and Figures 4 and 5, we can draw the following conclusions.

(1) Both the MOE-SG algorithm and the AM-SG algorithm can estimate the unknown parameters directly.

(2) The parameter estimation errors become smaller and smaller and go to zero with $t$ increasing.

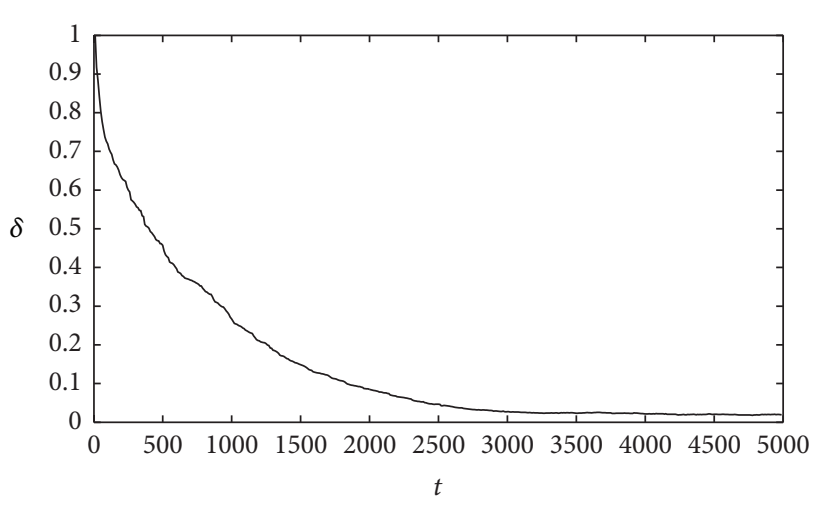

Figure 4: The parameter estimation errors $\delta$ versus $t$ (MOE-SG).

\section{Conclusions}

Two identification methods for dual-rate nonlinear outputerror systems are presented to estimate the unknown parameters directly and can avoid estimating more parameters than the original systems. Furthermore, the two methods can also be extended to other systems such as

$$
\begin{gathered}
y(t)=\frac{B(z)}{A(z)} f(u(t))+\frac{D(z)}{C(z)} v(t), \\
A(z) y(t)=B(z) f(u(t))+D(z) v(t) .
\end{gathered}
$$




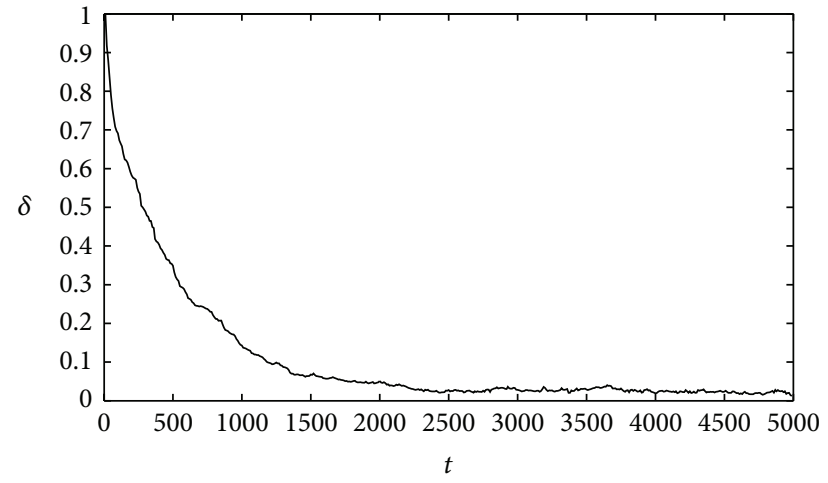

FIGURE 5: The parameter estimation errors $\delta$ versus $t$ (AM-SG).

\section{Conflict of Interests}

The authors declare that there is no conflict of interests regarding the publication of this paper.

\section{Acknowledgments}

This work was supported by the National Natural Science Foundation of China and supported by the Natural Science Foundation of Jiangsu Province (no. BK20131109).

\section{References}

[1] F. Ding, System Identification-New Theory and Methods, Science Press, Beijing, China, 2013.

[2] F. Ding, System Identification-Performances Analysis for Identification Methods, Science Press, Beijing, China, 2014.

[3] Y. Liu, Y. Xiao, and X. Zhao, "Multi-innovation stochastic gradient algorithm for multiple-input single-output systems using the auxiliary model," Applied Mathematics and Computation, vol. 215, no. 4, pp. 1477-1483, 2009.

[4] Y. Liu, L. Xie, and F. Ding, "An auxiliary model based on a recursive least-squares parameter estimation algorithm for non-uniformly sampled multirate systems," Proceedings of the Institution of Mechanical Engineers: Journal of Systems and Control Engineering, vol. 223, no. 4, pp. 445-454, 2009.

[5] Y. Liu, J. Sheng, and R. F. Ding, "Convergence of stochastic gradient estimation algorithm for multivariable ARX-like systems," Computers and Mathematics with Applications, vol. 59, no. 8, pp. 2615-2627, 2010.

[6] Y. J. Liu and R. Ding, "Consistency of the extended gradient identification algorithm for multi-input multi-output systems with moving average noises," International Journal of Computer Mathematics, vol. 90, no. 9, pp. 1840-1852, 2013.

[7] F. Ding and T. Chen, "Performance bounds of forgetting factor least-squares algorithms for time-varying systems with finite measurement data," IEEE Transactions on Circuits and Systems I: Regular Papers, vol. 52, no. 3, pp. 555-566, 2005.

[8] F. Ding, Y. Shi, and T. Chen, "Performance analysis of estimation algorithms of nonstationary ARMA processes," IEEE Transactions on Signal Processing, vol. 54, no. 3, pp. 1041-1053, 2006.

[9] F. Ding, T. Chen, and L. Qiu, "Bias compensation based recursive least-squares identification algorithm for MISO systems,"
IEEE Transactions on Circuits and Systems II: Express Briefs, vol. 53, no. 5, pp. 349-353, 2006.

[10] F. Ding, H. Yang, and F. Liu, "Performance analysis of stochastic gradient algorithms under weak conditions," Science in China F: Information Sciences, vol. 51, no. 9, pp. 1269-1280, 2008.

[11] F. Ding, "Coupled-least-squares identification for multivariable systems," IET Control Theory and Applications, vol. 7, no. 1, pp. 68-79, 2013.

[12] F. Ding, X. G. Liu, and J. Chu, "Gradient-based and leastsquares-based iterative algorithms for Hammerstein systems using the hierarchical identification principle," IET Control Theory and Applications, vol. 7, pp. 176-184, 2013.

[13] D. Wang and F. Ding, "Least squares based and gradient based iterative identification for Wiener nonlinear systems," Signal Processing, vol. 91, no. 5, pp. 1182-1189, 2011.

[14] D. Q. Wang and F. Ding, "Hierarchical least squares estimation algorithm for Hammerstein-Wiener systems," IEEE Signal Processing Letters, vol. 19, no. 12, pp. 825-828, 2012.

[15] D. Q. Wang, F. Ding, and Y. Y. Chu, "Data filtering based recursive least squares algorithm for Hammerstein systems using the key-term separation principle," Information Sciences, vol. 222, pp. 203-212, 2013.

[16] D. Q. Wang, F. Ding, and X. M. Liu, "Least squares algorithm for an input nonlinear system with a dynamic subspace state space model," Nonlinear Dynamics, vol. 75, no. 1-2, pp. 49-61, 2014.

[17] J. Chen, Y. Zhang, and R. F. Ding, "Auxiliary model based multiinnovation algorithms for multivariable nonlinear systems," Mathematical and Computer Modelling, vol. 52, no. 9-10, pp. 1428-1434, 2010.

[18] J. Chen, X. Wang, and R. F. Ding, "Gradient based estimation algorithm for Hammerstein systems with saturation and deadzone nonlinearities," Applied Mathematical Modelling, vol. 36, no. 1, pp. 238-243, 2012.

[19] J. Chen and F. Ding, "Least squares and stochastic gradient parameter estimation for multivariable nonlinear Box-Jenkins models based on the auxiliary model and the multi-innovation identification theory," Engineering Computations, vol. 29, no. 8, pp. 907-921, 2012.

[20] J. Chen, Y. Zhang, and R. F. Ding, "Gradient-based parameter estimation for input nonlinear systems with ARMA noises based on the auxiliary model," Nonlinear Dynamics, vol. 72, no. 4, pp. 865-871, 2013.

[21] F. Ding, L. Qiu, and T. Chen, "Reconstruction of continuoustime systems from their non-uniformly sampled discrete-time systems," Automatica, vol. 45, no. 2, pp. 324-332, 2009.

[22] F. Ding and J. Ding, "Least-squares parameter estimation for systems with irregularly missing data," International Journal of Adaptive Control and Signal Processing, vol. 24, no. 7, pp. 540553, 2010.

[23] F. Ding, P. X. Liu, and G. Liu, "Multiinnovation least-squares identification for system modeling," IEEE Transactions on Systems, Man, and Cybernetics B: Cybernetics, vol. 40, no. 3, pp. 767-778, 2010.

[24] Y. J. Liu, F. Ding, and Y. Shi, "Least squares estimation for a class of non-uniformly sampled systems based on the hierarchical identification principle," Circuits, Systems and Signal Processing, vol. 31, no. 6, pp. 1985-2000, 2012.

[25] F. Ding, G. Liu, and X. P. Liu, "Partially coupled stochastic gradient identification methods for non-uniformly sampled systems," IEEE Transactions on Automatic Control, vol. 55, no. 8, pp. 1976-1981, 2010. 
[26] J. Ding, F. Ding, X. P. Liu, and G. Liu, "Hierarchical least squares identification for linear SISO systems with dual-rate sampleddata," IEEE Transactions on Automatic Control, vol. 56, no. 11, pp. 2677-2683, 2011.

[27] F. Ding, G. Liu, and X. P. Liu, "Parameter estimation with scarce measurements," Automatica, vol. 47, no. 8, pp. 1646-1655, 2011.

[28] J. Chen, "Several gradient parameter estimation algorithms for dual-rate sampled systems," Journal of the Franklin Institute. Engineering and Applied Mathematics, vol. 351, no. 1, pp. 543$554,2014$.

[29] J. Chen and R. Ding, "An auxiliary-model-based stochastic gradient algorithm for dual-rate sampled-data Box-Jenkins systems," Circuits Systems and Signal Processing, vol. 32, no. 5, pp. 2475-2485, 2013.

[30] J. Ding, Y. Shi, H. Wang, and F. Ding, "A modified stochastic gradient based parameter estimation algorithm for dual-rate sampled-data systems," Digital Signal Processing: A Review Journal, vol. 20, no. 4, pp. 1238-1247, 2010.

[31] Y. Shi and B. Yu, “Output feedback stabilization of networked control systems with random delays modeled by Markov chains," IEEE Transactions on Automatic Control, vol. 54, no. 7, pp. 1668-1674, 2009.

[32] Y. Shi and H. Fang, "Kalman filter-based identification for systems with randomly missing measurements in a network environment," International Journal of Control, vol. 83, no. 3, pp. 538-551, 2010.

[33] Y. Shi and B. Yu, "Robust mixed $\mathrm{H} 2 / \mathrm{H}_{\infty}$ control of networked control systems with random time delays in both forward and backward communication links," Automatica, vol. 47, no. 4, pp. 754-760, 2011.

[34] F. Ding and T. Chen, "Least squares based self-tuning control of dual-rate systems," International Journal of Adaptive Control and Signal Processing, vol. 18, no. 8, pp. 697-714, 2004.

[35] F. Ding and T. Chen, "A gradient based adaptive control algorithm for dual-rate systems," Asian Journal of Control, vol. 8, no. 4, pp. 314-323, 2006.

[36] F. Ding, T. Chen, and Z. Iwai, "Adaptive digital control of Hammerstein nonlinear systems with limited output sampling," SIAM Journal on Control and Optimization, vol. 45, no. 6, pp. 2257-2276, 2007.

[37] J. Zhang, F. Ding, and Y. Shi, "Self-tuning control based on multi-innovation stochastic gradient parameter estimation," Systems and Control Letters, vol. 58, no. 1, pp. 69-75, 2009.

[38] Y. Shi, F. Ding, and T. Chen, "Multirate crosstalk identification in xDSL systems," IEEE Transactions on Communications, vol. 54, no. 10, pp. 1878-1886, 2006.

[39] Y. J. Liu, F. Ding, and Y. Shi, "An efficient hierarchical identification method for general dual-rate sampled-data systems," Automatica, vol. 50, no. 3, pp. 962-973, 2014.

[40] F. Ding and T. Chen, "Identification of dual-rate systems based on finite impulse response models," International Journal of Adaptive Control and Signal Processing, vol. 18, no. 7, pp. 589598, 2004.

[41] F. Ding and T. Chen, "Combined parameter and output estimation of dual-rate systems using an auxiliary model," Automatica, vol. 40, no. 10, pp. 1739-1748, 2004.

[42] F. Ding and T. Chen, "Parameter estimation of dual-rate stochastic systems by using an output error method," IEEE Transactions on Automatic Control, vol. 50, no. 9, pp. 1436-1441, 2005.
[43] F. Ding and T. Chen, "Hierarchical identification of lifted statespace models for general dual-rate systems," IEEE Transactions on Circuits and Systems I: Regular Papers, vol. 52, no. 6, pp. 11791187, 2005.

[44] F. Ding, P. X. Liu, and Y. Shi, "Convergence analysis of estimation algorithms for dual-rate stochastic systems," Applied Mathematics and Computation, vol. 176, no. 1, pp. 245-261, 2006.

[45] F. Ding, P. X. Liu, and H. Yang, "Parameter identification and intersample output estimation for dual-rate systems," IEEE Transactions on Systems, Man, and Cybernetics A: Systems and Humans, vol. 38, no. 4, pp. 966-975, 2008.

[46] J. Li and F. Ding, "Maximum likelihood stochastic gradient estimation for Hammerstein systems with colored noise based on the key term separation technique," Computers and Mathematics with Applications, vol. 62, no. 11, pp. 4170-4177, 2011.

[47] X. L. Li, L. C. Zhou, R. Ding, and J. Shing, "Recursive leastsquares estimation for Hammerstein nonlinear systems with nonuniform sampling," Mathematical Problems in Engineering, vol. 2013, Article ID 240929, 8 pages, 2013.

[48] F. Ding, X. P. Liu, and G. Liu, "Identification methods for Hammerstein nonlinear systems," Digital Signal Processing: A Review Journal, vol. 21, no. 2, pp. 215-238, 2011.

[49] F. Ding, "Hierarchical multi-innovation stochastic gradient algorithm for Hammerstein nonlinear system modeling," Applied Mathematical Modelling, vol. 37, no. 4, pp. 1694-1704, 2013.

[50] J. H. Li, "Parameter estimation for Hammerstein CARARMA systems based on the Newton iteration," Applied Mathematics Letters, vol. 26, no. 1, pp. 91-96, 2013.

[51] D. Wang, Y. Chu, and F. Ding, "Auxiliary model-based RELS and MI-ELS algorithm for Hammerstein OEMA systems," Computers and Mathematics with Applications, vol. 59, no. 9, pp. 3092-3098, 2010.

[52] J. Vörös, "Modeling and parameter identification of systems with multisegment piecewise-linear characteristics," IEEE Transactions on Automatic Control, vol. 47, no. 1, pp. 184-188, 2002.

[53] J. Vörös, "Modeling and identification of systems with backlash," Automatica, vol. 46, no. 2, pp. 369-374, 2010.

[54] F. Ding, Y. Shi, and T. Chen, "Auxiliary model-based leastsquares identification methods for Hammerstein output-error systems," Systems and Control Letters, vol. 56, no. 5, pp. 373-380, 2007.

[55] F. Ding, P. X. Liu, and G. Liu, "Auxiliary model based multiinnovation extended stochastic gradient parameter estimation with colored measurement noises," Signal Processing, vol. 89, no. 10, pp. 1883-1890, 2009.

[56] F. Ding and Y. Gu, "Performance analysis of the auxiliary model based least squares identification algorithm for one-step state delay systems," International Journal of Computer Mathematics, vol. 89, no. 15, pp. 2019-2028, 2012.

[57] F. Ding and Y. Gu, "Performance analysis of the auxiliary modelbased stochastic gradient parameter estimation algorithm for state space systems with one-step state delay," Circuits, Systems and Signal Processing, vol. 32, no. 2, pp. 585-599, 2013.

[58] F. Ding, Y. Liu, and B. Bao, "Gradient-based and least-squaresbased iterative estimation algorithms for multi-input multioutput systems," Proceedings of the Institution of Mechanical Engineers I: Journal of Systems and Control Engineering, vol. 226, no. 1, pp. 43-55, 2012.

[59] F. Ding, P. X. Liu, and G. Liu, "Gradient based and leastsquares based iterative identification methods for $\mathrm{OE}$ and 
OEMA systems," Digital Signal Processing, vol. 20, no. 3, pp. 664-677, 2010.

[60] F. Ding, "Decomposition based fast least squares algorithm for output error systems," Signal Processing, vol. 93, no. 5, pp. 12351242, 2013.

[61] Y. Liu, D. Wang, and F. Ding, "Least squares based iterative algorithms for identifying Box-Jenkins models with finite measurement data," Digital Signal Processing, vol. 20, no. 5, pp. 14581467, 2010.

[62] D. Q. Wang, "Least squares-based recursive and iterative estimation for output error moving average systems using data filtering," IET Control Theory and Applications, vol. 5, no. 14, pp. 1648-1657, 2011.

[63] F. Ding and T. Chen, "Performance analysis of multi-innovation gradient type identification methods," Automatica, vol. 43, no. 1, pp. 1-14, 2007.

[64] F. Ding, "Several multi-innovation identification methods," Digital Signal Processing, vol. 20, no. 4, pp. 1027-1039, 2010.

[65] F. Ding, H. Chen, and M. Li, "Multi-innovation least squares identification methods based on the auxiliary model for MISO systems," Applied Mathematics and Computation, vol. 187, no. 2 , pp. 658-668, 2007.

[66] L. Han and F. Ding, "Multi-innovation stochastic gradient algorithms for multi-input multi-output systems," Digital Signal Processing, vol. 19, no. 4, pp. 545-554, 2009.

[67] D. Wang and F. Ding, "Performance analysis of the auxiliary models based multi-innovation stochastic gradient estimation algorithm for output error systems," Digital Signal Processing, vol. 20, no. 3, pp. 750-762, 2010.

[68] L. Xie, Y. J. Liu, H. Z. Yang, and F. Ding, "Modelling and identification for non-uniformly periodically sampled-data systems," IET Control Theory and Applications, vol. 4, no. 5, pp. 784-794, 2010.

[69] Y. Liu, L. Yu, and F. Ding, "Multi-innovation extended stochastic gradient algorithm and its performance analysis," Circuits, Systems, and Signal Processing, vol. 29, no. 4, pp. 649-667, 2010.

[70] L. Han and F. Ding, "Identification for multirate multi-input systems using the multi-innovation identification theory," Computers and Mathematics with Applications, vol. 57, no. 9, pp. 1438-1449, 2009.

[71] F. Ding and T. Chen, "Hierarchical gradient-based identification of multivariable discrete-time systems," Automatica, vol. 41, no. 2, pp. 315-325, 2005.

[72] F. Ding and T. Chen, "Hierarchical least squares identification methods for multivariable systems," IEEE Transactions on Automatic Control, vol. 50, no. 3, pp. 397-402, 2005.

[73] H. Han, L. Xie, F. Ding, and X. Liu, "Hierarchical least-squares based iterative identification for multivariable systems with moving average noises," Mathematical and Computer Modelling, vol. 51, no. 9-10, pp. 1213-1220, 2010.

[74] Z. Zhang, F. Ding, and X. Liu, "Hierarchical gradient based iterative parameter estimation algorithm for multivariable output error moving average systems," Computers and Mathematics with Applications, vol. 61, no. 3, pp. 672-682, 2011.

[75] D. Q. Wang, R. Ding, and X. Z. Dong, "Iterative parameter estimation for a class of multivariable systems based on the hierarchical identification principle and the gradient search," Circuits, Systems and Signal Processing, vol. 31, no. 6, pp. 21672177, 2012.

[76] F. Ding and T. Chen, "On iterative solutions of general coupled matrix equations," SIAM Journal on Control and Optimization, vol. 44, no. 6, pp. 2269-2284, 2006.
[77] F. Ding, P. X. Liu, and J. Ding, "Iterative solutions of the generalized Sylvester matrix equations by using the hierarchical identification principle," Applied Mathematics and Computation, vol. 197, no. 1, pp. 41-50, 2008.

[78] F. Ding and T. Chen, "Gradient based iterative algorithms for solving a class of matrix equations," IEEE Transactions on Automatic Control, vol. 50, no. 8, pp. 1216-1221, 2005.

[79] F. Ding and T. Chen, "Iterative least-squares solutions of coupled Sylvester matrix equations," Systems and Control Letters, vol. 54, no. 2, pp. 95-107, 2005.

[80] F. Ding, "Transformations between some special matrices," Computers and Mathematics with Applications, vol. 59, no. 8, pp. 2676-2695, 2010.

[81] L. Xie, J. Ding, and F. Ding, "Gradient based iterative solutions for general linear matrix equations," Computers and Mathematics with Applications, vol. 58, no. 7, pp. 1441-1448, 2009.

[82] J. Ding, Y. Liu, and F. Ding, "Iterative solutions to matrix equations of the form $A_{i} X B_{i}=F_{i}$," Computers and Mathematics with Applications, vol. 59, no. 11, pp. 3500-3507, 2010.

[83] L. Xie, Y. Liu, and H. Yang, "Gradient based and least squares based iterative algorithms for matrix equations $A X B+C X^{T} D=$ F," Applied Mathematics and Computation, vol. 217, no. 5, pp. 2191-2199, 2010.

[84] F. Ding, "Two-stage least squares based iterative estimation algorithm for CARARMA system modeling," Applied Mathematical Modelling, vol. 37, no. 7, pp. 4798-4808, 2013.

[85] F. Ding and H. H. Duan, "Two-stage parameter estimation algorithms for Box-Jenkins systems," IET Signal Processing, vol. 7, no. 8, pp. 646-654, 2013.

[86] J. Ding and F. Ding, "Bias compensation-based parameter estimation for output error moving average systems," International Journal of Adaptive Control and Signal Processing, vol. 25, no. 12, pp. 1100-1111, 2011.

[87] Y. Zhang, "Unbiased identification of a class of multi-input single-output systems with correlated disturbances using bias compensation methods," Mathematical and Computer Modelling, vol. 53, no. 9-10, pp. 1810-1819, 2011.

[88] Y. Zhang and G. Cui, "Bias compensation methods for stochastic systems with colored noise," Applied Mathematical Modelling, vol. 35, no. 4, pp. 1709-1716, 2011.

[89] F. Ding, "Combined state and least squares parameter estimation algorithms for dynamic systems," Applied Mathematical Modelling, vol. 38, no. 1, pp. 403-412, 2014.

[90] F. Ding, X. M. Liu, H. B. Chen, and G. Y. Yao, "Hierarchical gradient based and hierarchical least squares based iterative parameter identification for CARARMA systems," Signal Processing, vol. 97, pp. 31-39, 2014.

[91] P. P. Hu and F. Ding, "Multistage least squares based iterative estimation for feedback nonlinear systems with moving average noises using the hierarchical identification principle," Nonlinear Dynamics, vol. 73, no. 1-2, pp. 583-592, 2013.

[92] J. Li, F. Ding, and G. Yang, "Maximum likelihood least squares identification method for input nonlinear finite impulse response moving average systems," Mathematical and Computer Modelling, vol. 55, no. 3-4, pp. 442-450, 2012.

[93] F. Ding and T. Chen, "Identification of Hammerstein nonlinear ARMAX systems," Automatica, vol. 41, no. 9, pp. 1479-1489, 2005.

[94] F. Ding, Y. Shi, and T. Chen, "Gradient-based identification methods for hammerstein nonlinear ARMAX models," Nonlinear Dynamics, vol. 45, no. 1-2, pp. 31-43, 2006. 
[95] J. H. Li, F. Ding, and L. Hua, "Maximum likelihood Newton recursive and the Newton iterative estimation algorithms for Hammerstein CARAR systems," Nonlinear Dynamics, vol. 75, no. 1-2, pp. 234-245, 2014.

[96] X. Luan, P. Shi, and F. Liu, "Stabilization of networked control systems with random delays," IEEE Transactions on Industrial Electronics, vol. 58, no. 9, pp. 4323-4330, 2011.

[97] X. L. Luan, S. Y. Zhao, and F. Liu, "H-infinity control for discrete-time markov jump systems with uncertain transition probabilities," IEEE Transactions on Automatic Control, vol. 58, no. 6, pp. 1566-1572, 2013.

[98] J. Chen, L. X. Lu, and R. Ding, "Parameter identification of systems with preload nonlinearities based on the finite impulse response model and negative gradient search," Applied Mathematics and Computation, vol. 219, no. 5, pp. 2498-2505, 2012.

[99] J. Chen, L. Lv, and R. F. Ding, "Multi-innovation stochastic gradient algorithms for dual-rate sampled systems with preload nonlinearity," Applied Mathematics Letters, vol. 26, no. 1, pp. 124-129, 2013. 


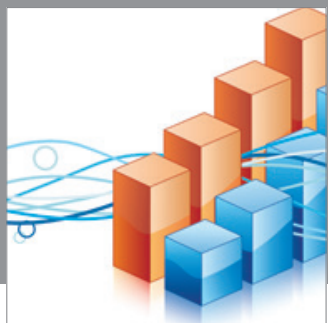

Advances in

Operations Research

mansans

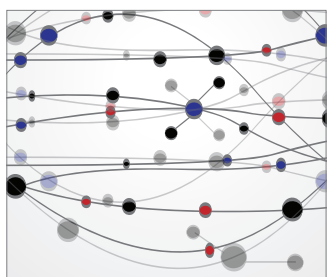

The Scientific World Journal
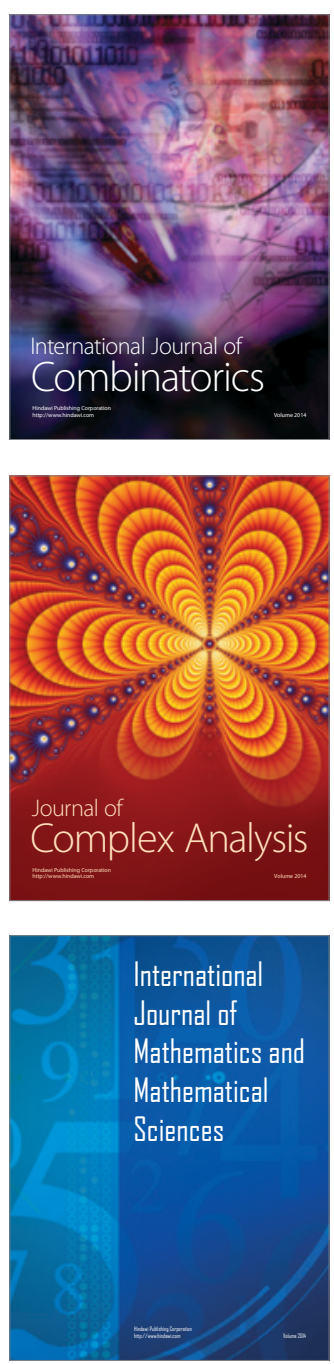
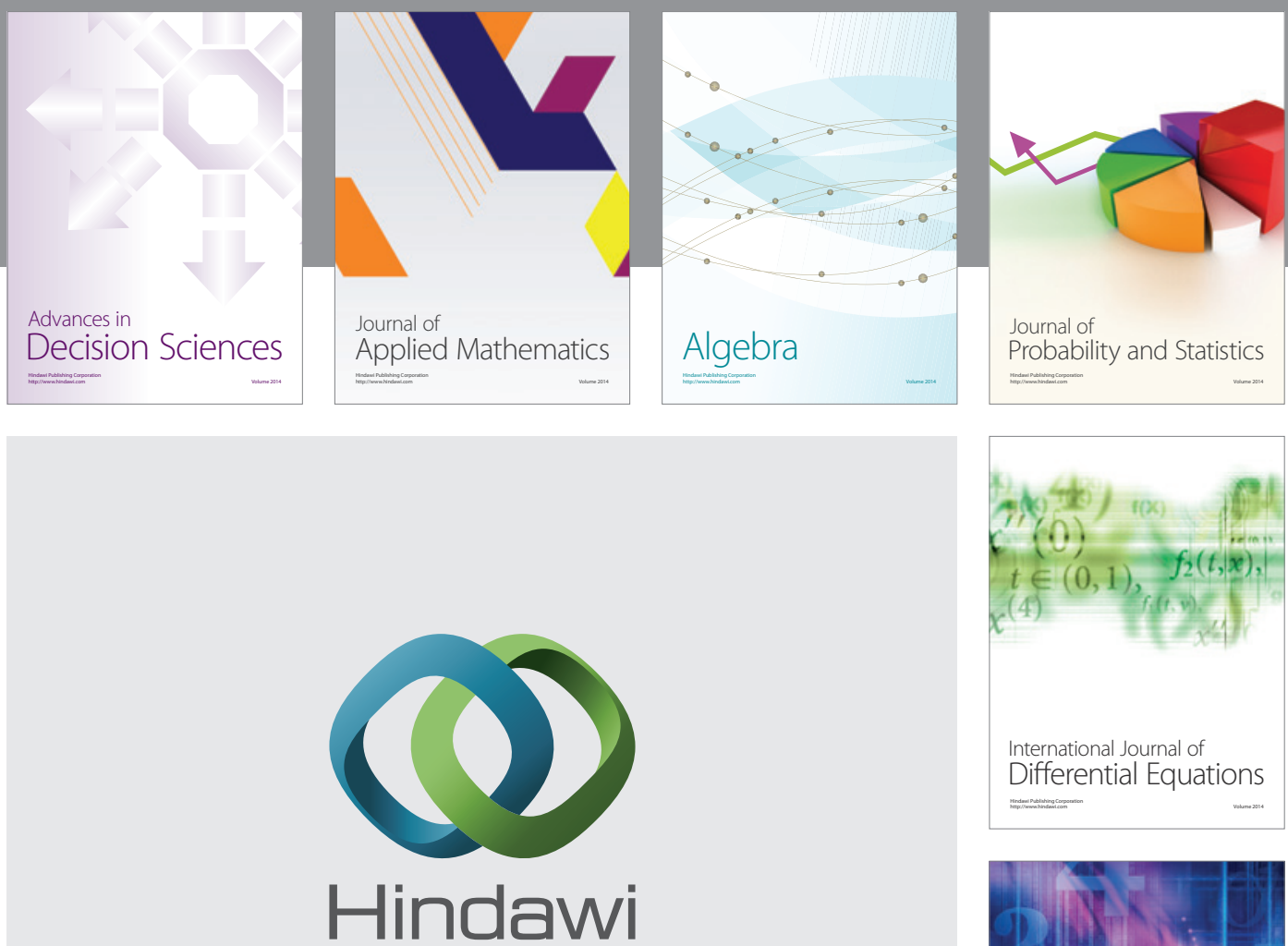

Submit your manuscripts at http://www.hindawi.com
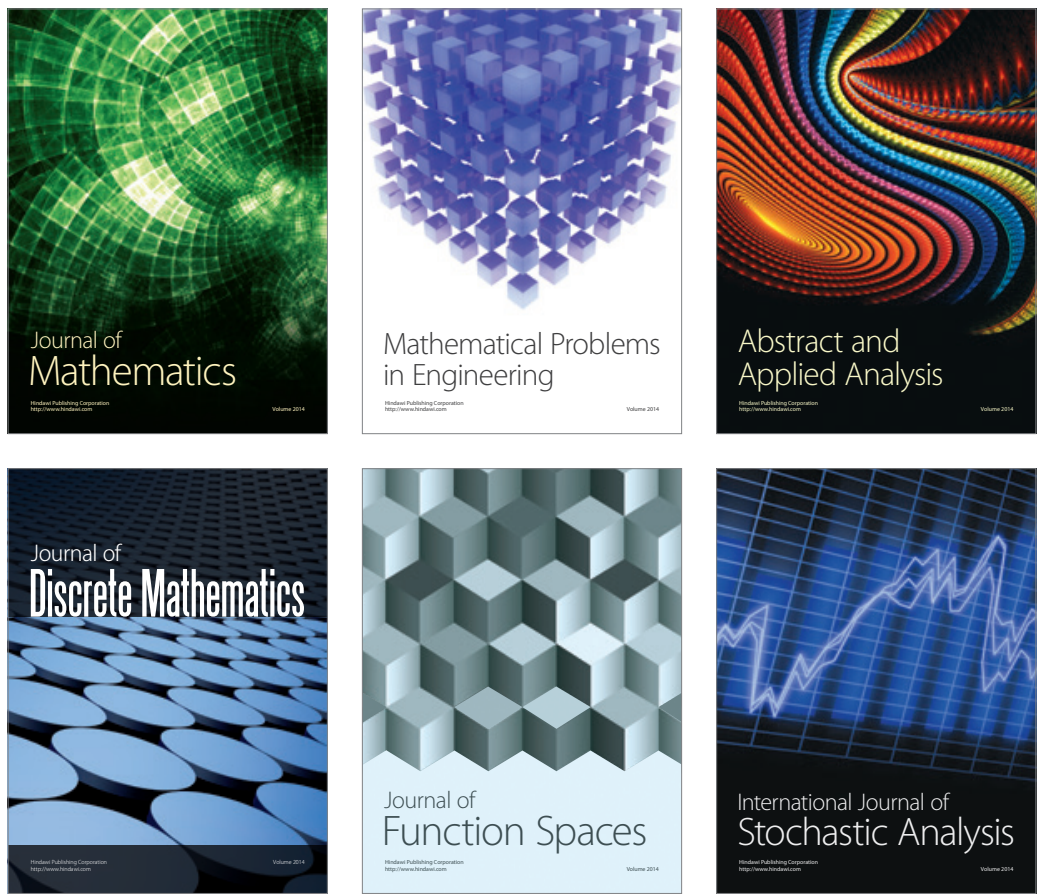

Journal of

Function Spaces

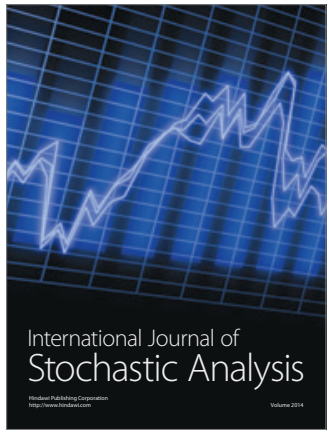

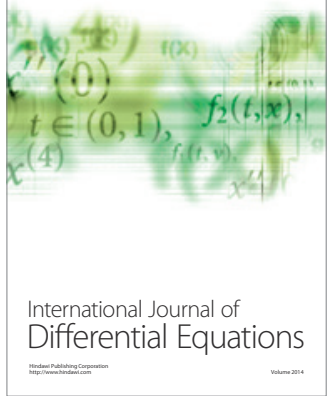
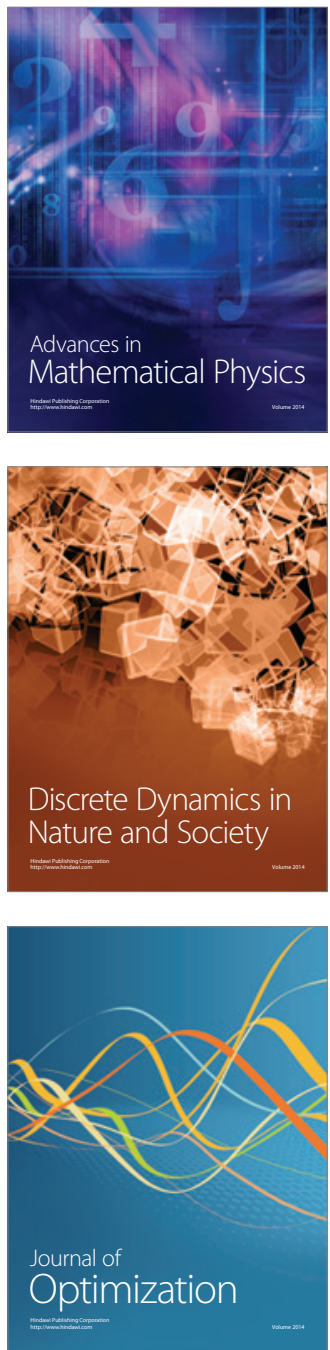